\title{
JANU SIRSASANA: KONSEP DAN MANFAATNYA BAGI KESEHATAN DIRI
}

\author{
I Gusti Made Widya Sena \\ Institut Hindu Dharma Negeri Denpasar \\ Email: gusti_sena@yahoo.com
}

\begin{abstract}
:
Yoga is union. Unification between the individual soul and the universal soul. Unite the body with mind and mind with the soul. Knowledge of yoga can help to maintain the purity of soul by doing movements or poses on his body. Sirsasana pose is one of the poses that can be used for many people whose work is mostly spent behind a desk or computer. By working behind a desk or computer, someone will spend hours and sitting and keeping his body awake. In addition to maintaining the natural functions of the pelvis and lower back, the sitting position in yoga also has to do with training at a more advanced level. The word "asana" can actually be interpreted literally as sitting. And from a certain perspective, all asana exercises can be seen as a methodical way to free the spine, legs and breathing, so that yoga practitioners can be in a sitting position for a long time.
\end{abstract}

Keywords: Yoga, Janu Sirsasana, Health

\begin{abstract}
Abstrak:
Yoga adalah penyatuan. Penyatuan antara jiwa individual dengan jiwa yang universal. Menyatukan tubuh dengan pikiran dan pikiran dengan jiwa. Pengetahuan yoga dapat membantu seseorang untuk menjaga kesucian jiwanya dengan melakukan gerak atau pose pada tubuhnya. Pose janu sirsasana merupakan salah satu pose yang dapat digunakan bagi banyak orang yang waktu pekerjaannya sebagian besar dihabiskan di balik meja kerja atau komputer. Dengan bekerja di balik meja atau komputer, seseorang akan menghabiskan waktunya selama berjam-jam untuk duduk dan membuat tubuhnya tetap terjaga. Selain menjaga fungsi alami panggul dan punggung bawah, posisi duduk dalam yoga juga memiliki kaitan dengan latihan pada tingkat yang lebih lanjut. Kata "asana" sebenarnya dapat diartikan secara harfiah sebagai "duduk". Dan dari perspektif tertentu, semua latihan asana dapat dipandang sebagai cara metodis untuk membebaskan tulang belakang, tungkai dan pernapasan, sehingga pelaku yoga dapat berada dalam posisi duduk dalam waktu yang lama.
\end{abstract}

Kata Kunci: Yoga, Janu Sirsasana, Kesehatan 


\section{PENDAHULUAN}

Perkembangan postur dan pose dalam peradaban di India telah ada sejak zaman primitif. Pada masa itu bahasa tidak begitu berkembang, seseorang masih menggunakan tanda-tanda ataupunberbagaisimboldalammelakukanaktivitas kesehariannya. Ilustrasi dan praktik dilakukan untuk mengkomunikasikan perasaan mereka terhadap dirinya dan orang lain. Ini dilakukan agar memudahkan bagi mereka dalam berkomunikasi antara satu dengan yang lainnya. Dewasa ini seseorang akan bekerja untuk mencukupi kebutuhan hidupnya sehari-hari, mulai dengan pemenuhan kebutuhan pangan, sandang, papan hingga kebutuhan tersier akan diikutinya sebagai bentuk dari pemuasan hasrat dan kesenangan indera. Berbagai keinginan yang selaras dengan perkembangan lingkungan dan tuntutan jaman membuat seseorang menjadi pribadi yang estetis dan kaku, karena lebih mengutamakan suasana hatinya dalam bertindak terhadap dunia luar. Kaku yang dimaksud sebagian besar adalah kelompok introvert yang tidak hanya membuat seseorang menjadi pribadi yang pesimis, tanpa kompromi, tidak fleksibel hingga menarik diri dari kehidupan sosial. Namun juga kaku yang dimaksud adalah yang melibatkan terganggunya fungsi fisiologi tubuh seseorang sehingga ia merasa tidak nyaman dalam melakukan aktivitas hidupnya sehari-hari.

Yoga adalah penyatuan. Penyatuan antara jiwa individual dengan jiwa yang universal. Menyatukan tubuh dengan pikiran dan pikiran dengan jiwa. Pengetahuan yoga dapat membantu seseorang untuk menjaga kesucian jiwanya dengan melakukan gerak atau pose pada tubuhnya. Pose janu sirsasana merupakan salah satu pose yang dapat digunakan bagi banyak orang yang waktu pekerjaannya sebagian besar dihabiskan di balik meja kerja atau komputer. Dengan bekerja di balik meja atau komputer, seseorang akan menghabiskan waktunya selama berjam-jam untuk duduk dan membuat tubuhnya tetap terjaga. Hal ini tanpa disadari akan menyebabkan epidemi nyeri punggung, pinggang dan pinggul pada masyarakat modern.

Kesatuan yang holistik dalam yoga adalah dengan memahami pengetahuan dan mempraktekkannya dalam kehidupan seharihari. Pengetahuan akan menjadi sia-sia tanpa dipraktekkan dan dibagikan kepada orang lain, begitupun sebaliknya praktek yang dilakukan tanpa didasari dengan pengetahuan layaknya sebuah intan yang tertutup oleh debu dan tanah, keindahannya tidak akan tampak dari dalam dirinya. Asana, mudra, bandha dan pranayama adalah empat unsur dalam yoga yang membantu seseorang dalam tahap pertama untuk mencari kesehatan tubuh materi dan tubuh spritualnya.

Asana seperti juga pose dengan menggunakan kedua kaki telanjang telah mengembangkan relasi baru dengan bumi melalui latihan postur (asana) duduk. Pinggul, pinggang, punggung, panggul dan tulang belakang bawah telah mengembangkan relasi baru dengan bumi saat seseorang menahan beban langsung di atasnya dengan postur duduk di atas bumi. Selain menjaga fungsi alami panggul dan punggung bawah, posisi duduk dalam yoga juga memiliki kaitan dengan latihan pada tingkat yang lebih lanjut. Kata "asana" sebenarnya dapat diartikan secara harfiah sebagai "duduk". Dan dari perspektif tertentu, semua latihan asana dapat dipandang sebagai cara metodis untuk membebaskan tulang belakang, tungkai dan pernapasan, sehingga pelaku yoga dapat berada dalam posisi duduk dalam waktu yang lama. Pada perubahan tubuh ini, gangguan antara gravitasi dan pernapasan dapat menghilang serta membebaskan energi tubuh untuk melakukan latihan meditasi yang lebih kontemplatif. Berdasarkan latar belakang di atas, penulis tertarik mengangkat tulisan ini karena sebelumnya belum pernah ada tulisan atau artikel ilmiah terkait tema yang penulis angkat. Selain itu dengan menulis artikel ini diharapkan agar nantinya artikel-artikel ilmiah yang sejenis semakin banyak berkembang dan memberikan sumbangan bagi dunia pengetahuan dan kesehatan modern. 


\section{PEMBAHASAN}

\subsection{Kelenjar Makhluk Hidup}

Di alam ini terdapat makhluk hidup yang belum berkembang dan tidak memiliki sel-sel saraf atau jaringan saraf, yang dimiliki sebagian besar adalah hanya menggunakan insting saja untuk melakukan segala aktivitas hidupnya. Manusia memiliki sel-sel saraf dan serabut saraf, namun mereka juga kadangkala berperilaku sesuai dengan insting mereka. Contohnya, seorang anak kecil tersenyum dan merapatkan tangannya karena insting mereka. Dalam hal ini mereka tidak diminta oleh pengetahuan atau kecendrungan intelektual apapun yang memintanya untuk melakukan hal itu.

Sel-sel saraf dan jaringan saraf dalam tubuh manusia yang tak terhitung jumlahnya itu dapat dibagi dalam dua jenis: yang satu menghubungkan otak dengan sumsum tulang belakang (punggung) yang disebut sistem saraf pusat dan yang satunya dari sumsum tulang punggung menuju kulit dan bagian dalam tubuh (sistem saraf cabang). Juga terdapat kumpulan sel-sel saraf dalam tengkorak yang terbentuk dari lemak yakni hypothalamus, yang memiliki kemampuan khusus, kemampuan bawaan lahir atau kekhususan getaran yang terkadang bersifat sintetik (sympathetik) dan terkadang apathetik (parasympathetik).

Dalam bahasa Sansekerta seluruh daerah kepala di atas telinga disebut snayupetaka yang berarti "sekeranjang saraf". Getaran dari bagian manapun pada tubuh memerlukan seper dua ratus detik untuk mencapai tempurung kepala. Misalnya seekor serangga menggigit tangan seseorang. Sensasi itu akan merambat melalui saraf-saraf aferen menuju otak. Pada saat itu dengan segera suatu perintah yang merambat melalui saraf-saraf eferen, diberikan untuk mengusir serangga itu. Istilah saraf-saraf aferen (menuju pusat) dan sarafsaraf eferen (dari pusat) berasal dari bahasa Latin yang masing-masing berarti "saraf-saraf sensorik" dan saraf-saraf motorik" padanan kata dari bahasa Sansekertanya adalah samjina nadi dan ajina nadi.
Sel-sel saraf selalu aktif dan bekerja secara langsung dalam keadaan pikiran yang sadar (consciouss, jagrata), bawah sadar (subconscious, svapna) dan tanpa sadar (unconscious, susupta). Meskipun istilah dalam bahasa Sansekerta, bahasa Indonesia dan bahasa Inggris untuk ketiga istilah keadaan pikiran itu tidaklah sama namun memiliki makna yang sama antara satu dengan yang lainnya. Ketika saraf-saraf tidak bekerja dengan semestinya, terkadang seseorang mengalami keadaan yang dapat digambarkan sebagai yang terkesima. Misalnya, ketika seseorang kepalanya terbentur keras di jalan/dinding dan hilanglah keseimbangan antara saraf-saraf aferen dan eferennya, maka ia bisa melupakan segalanya, kehilangan kemampuan memilah dan tidak dapat memutuskan apa yang harus dilakukan. Keadaan yang sama dapat terjadi setelah mimpi buruk. Apabila seseorang bermimpi ia dikerjar oleh hantu dan terjatuh serta kepalanya terantuk, ia bisa tiba-tiba terbangun dengan mandi keringat, serta menderita gejala-gejala yang sama seperti kalau kepalanya benar-benar terpukul dalam keadaan yang terjaga / sadar. Dalam keadaan demikian dapat dikatakan ia merasa pada keadaan yang lumpuh.

Titik tengah ruas terakhir dari tulang belakang adalah pusat saraf titik ini adalah titik pusat muladhara cakra. Seluruh tubuh berada dalam keadaan seimbang di cakra (plexus) ini. Disitu terdapat empat vrtti (kecendrungan) dharma (kerinduan psiko-spritual), artha (kerinduan psikis), kama (kerinduan fisik) dan moksa (kerinduan spiritual). Svadhistana cakra terletak pada sumsum tulang belakang tepat dibelakang pangkal alat kelamin. Cakra ini memiliki enam kecendrungan: avajina (mengecilkan orang lain), murccha (kelambanan secara psikis, kehilangan akal sehat), prashraya (kegemaran akan kepuasan), avishvasa (kurang percaya diri), sarvanasha (rasa pasti akan binasa) dan krurata (kekejaman).

Berikutnya adalah manipura cakra, cakra ini terletak pada pusar. Cakra ini mengendalikan 
sepuluh kecendrungan: lajja (rasa malu, memalukan), pishunata (cenderung sadis), lirsa (iri hati), susupti (lembam, mengantuk), visada (melankolia), kasaya (suka mengeluh, jengkel), trsna (hasrat memiliki), moha (tergila-gila), ghrna (benci, muak) dan bhaya (takut). Kemudian anahata cakra, terletak di tengah dada mengendalikan dua belas kecendrungan diantaranya: asha (harapan), cinta (khawatir), cesta (upaya), mamata (rasa memiliki, cinta), dambha (congkak/sombong), viveka (pemilahan), vikalata (lumpuh mental karena takut), ahamkara (ego), lolata (tamak), kapatata (munafik), vitarka (bohong) dan anutapa (sesal).

Lalu visuddha cakra terletak di daerah tenggorokan, yang mengendalikan enam belas kecendrungan seperti: bunyi burung merak, bunyi sapi jantan, suara kambing, suara rusa, suara burung tekukur, suara keledai, suara gajah, om kara, suara bangkitnya kundalini, penerapan teori, ekspresi pengetahuan duniawi, kesejahteraan dalam ranah yang halus, melakukan perbuatan mulia, pasrah pada Sang Agung, ekspresi menjijikan dan ekspresi manis. Kemudian di atasnya terdapat ajna cakra, yang terletak di antara alis mata, yang mengendalikan dua kecendrungan, yakni apara widya dan para widya atau pengetahuan duniawi dan pengetahuan spiritual. Cakra dalam bahasa Sanskerta sedangkan dalam bahasa Latin disebut dengan istilah plexus. Selain pusat-pusat saraf utama pada titik setiap cakra, terdapat juga banyak sub pusat tempat sub kelenjar itu berada. Semua sub kelenjar ini mempengaruhi dan mengendalikan kecendrungan-kecendrungan yang melekat pada setiap cakra.

\section{Definisi Janu Sirsasana}

Seseorang tidak akan pernah terpuaskan dengan sesuatu yang terbatas, dengan demikian, dalam pencarian akan hal yang tak terbatas, pertama-tama kita akan bertemu dengan pengetahuan estetika. Pengetahuan estetika tidaklah selalu berarti memperoleh sesuatu yang menyenangkan, sesuatu yang menarik. Ini dapat berarti memperoleh sesuatu yang menyusahkan dan sesuatu yang tidak mengenakkan. Jadi bisa saja menyenangkan atau bisa saja tidak.

Pengetahuan estetika adalah perasaan halus yang dimiliki seseorang sehingga dapat berekspresi dengan cara yang halus, dan bila tiba pada titik paling halusnya, titik itulah disebut sebagai puncak kemuliaan manusia. Ketika manusia mulai dalam gerakannya untuk mencari dan menuju Sang Agung, dalam pencarian kebahagiaan yang tertinggi, pertama-tama mereka akan berkontak dengan spritualitas. Begitu spritualitas menemukan kontak dengan Yang Tak Terbatas, yaitu ketika yang terbatas bertemu dengan yang tak terbatas, dari yang tidak sadar bertemu dengan kesadaran, inilah yang disebut dengan yoga.

Yoga adalah ketika suatu unit sedang bergerak mencari yang tak terbatas, yang terbatas bergerak menuju yang tak terbatas dalam media spiritual dan mistik. Dalam bahasa Sanskerta, yoga berarti "manunggal". Ibaratnya gula dan air, gula tidak mempertahankan identitasnya ketika menyatu dengan air. Inilah kemanunggalangan, dalam ranah mistisisme, yoga mempunyai arti kemanunggalangan yaitu kemanunggalangan seperti gula dan air.

Gerakan yoga ini demi manunggalnya unit pada Sang Agung, yang terbatas dengan yang tak terbatas. Struktur fisik dan psikis manusia sejalan dengan berbagai pose asanas yang telah ribuan tahun lalu ditemukan dan dikompilasikan oleh para maha resi untuk membantu manusia dalam memahami dan mencapai kesadaran tubuh fisik dan spritualnya.

Asana merupakan langkah ketiga dari delapan langkah (astangga yoga) yang dikompilasikan oleh Maha Rsi Patanjali dengan tujuan untuk membuat tubuh mantap bagi teknik-teknik yang lebih tinggi seperti pratyahara (penarikan inderaindera), dharana (konsentrasi), dhayana (meditasi) dan samadhi (realisasi kosmis). Dalam hatha 
yoga, yang diperhatikan lebih mendalam dengan menyiapkan tubuh pada teknik-teknik spiritual yang lebih tinggi, terutama ditujukan untuk menyucikan tubuh melalui asana. Semua teknikteknik tersebut digambarkan secara rinci dalam naskah kuno seperti Hatha Yoga Pradipika dan Gheranda Samhita. Meskipun asana itu sendiri tidak dapat memberikan kesadaran spiritual tetapi asana merupakan tahapan pada jalan spiritual.

Kata asana berasal dari bahasa Sanskerta, yang memiliki arti tetap, menjadi dan ditegakkan dalam posisi tertentu. Menurut Swami Satchidananda (1978:152), asana adalah pose (postur) yang mantap dan nyaman. Asana juga dijelaskan oleh Vasu (1979:3) dalam bukunya yang berjudul Gheranda Samhita. Menurutnya asana adalah melakukan pose atau postur yang akan memberikan driddhata atau kekuatan. Kekuatan yang dimaksud disini tidak hanya kekuatan fisik, namun juga kekuatan mental dan pikiran dapat dimiliki seseorang yang disiplin melakukan asana. Di lain sisi, Iyengar menyarankan bahwa dalam setiap melakukan pose asana sebaiknya dilakukan dengan memfokuskan diri dan pikiran pada otot, kalenjar dan saraf. Menurutnya tubuh yang elastis dan diregangkan akan melindungi seseorang dari kelelahan dan memberikan kenyamanan pada sistem saraf di tubuh.

Pada umumnya seseorang tidak dapat melatih asanas langsung dengan sempurna, seperti ilustrasi pada gambar/ foto ataupun video di berbagai buku yoga dan media sosial. Jika ingin melatih asanas sebaiknya lakukan dengan wajar dan tidak memaksakan diri. Lakukan pose asanas semampu yang dapat kita lakukan dengan sikap yang nyaman dan tahan pose tersebut dalam beberapa waktu agar otot, kelenjar dan sendi diberikan pelumas dan fleksibel. Didalam asanas tidak ada ketegangan, latihan yang berlebihan dapat menyebabkan luka yang membuat anda tidak dapat meneruskan latihan dalam waktu yang lama.

Orang yang tidak terbiasa dengan latihan setiap hari harus berlatih dengan bertahap. Asanas berbeda dengan berbagai olahraga berat lainnya, tarian dan balet, sehingga mereka yang telah terbiasa dan terlatih dengan bidang tersebutpun harus berlatih dengan sangat hati-hati. Dalam hidupnya seseorang tidak boleh melakukan asanas setelah menjalani operasi sampai benar-benar sembuh dan tidak merasakan sakit. Jika merasa sakit pada saat melakukan asanas, sebaiknya harus berhenti sesaat dan rileks agar sembuh. Selalu lakukan pose shavasana setelah melakukan asanas hingga denyut jantung dan pernapasan kembali normal, bukan sebaliknya lelah.

Hindari melakukan asanas dengan kondisi mental yang tidak semangat, malas dan menggerutu. Sebaliknya asanas sebaiknya dilakukan dengan keadaan tubuh dan mental yang semangat, nyaman dan gembira. Untuk itu pemilihan ruang dan waktu yang tepat sangat penting dalam melakukan asanas. Setiap pose tubuh harus dipertahankan dengan nyaman dan kapasitas fisik dirangsang untuk tumbuh. Tekanan yang dipertahankan ini akan mempengaruhi sekresi hormon dalam tubuh. Jangan lakukan asanas dengan terlalu cepat mengganti asanas dari satu pose ke pose lainnya. Asanas tidak diukur dengan seberapa banyak seseorang mampu melakukan pose melainkan seberapa cermat pose asana situ dilakukan dengan benar. Cermat berarti tepat dan benar dalam menggunakan dan mempraktekkan pranayama (pengaturan napas), asana (pose), mudra (sikap tangan, kaki dan kepala) dan bandha (kuncian).

Asanas yang dilakukan sebaiknya dipraktekkan dengan perlahan-lahan, rasakan tubuh kita adalah sebuah mesin dengan getarangetaran mesinnya yang membuat tubuh tetap lentuk dan sehat. Fokuskan pikiran untuk beristirahat seirama denyut napas dan setelah beberapa waktu, setelah melakukan dan menyelesaikan satu pose, istirahatkan tubuh sesaat lalu rasakan aliran gerak kita dikendalikan oleh aliran pernapasan kita yang lembut dan tenang, seperti air sungai yang mengalir tenang mencapai samudera. Lakukan 
asanas dengan pikiran yang tetap sadar dan mengalir, sehingga kita merasakan pose-pose yang kita lakukan layaknya langkah-langkah dalam tarian kosmik.

Seseorang yang melakukan meditasi sebaiknya berlatih asanas dua kali sehari, setelah meditasi pagi dan sore hari, ketika tubuh dan pikiran dalam keadaan rileks dan tenang. Dengan berlatih asanas dua kali sehari, maka tubuh dipersiapkan untuk melakukan berbagai aktivitas sehari-hari dan untuk beristirahat pada malamnya. Setiap latihan, seseorang harus berlatih paling sedikitnya empat macam asanas, diikuti oleh rileksasi dan meditasi. Setelah rileksasi jangan melakukan latihan dan pekerjaan yang berat karena akan membuat tubuh menjadi lelah.

Latihan ini dapat menyejukkan tubuh, merilekskan jantung dan saraf serta menenangkan pikiran sehingga dapat mencegah berbagai penyakit. Bahkan didalam musim dinginpun beberapa bagian tubuh tertentu menjadi panas karena penggunaan yang terus menerus dan sarafsarafnya hampir selalu dirangsang terutama di bagian mana pose itu maksimal dilakukan.

Dengan melakukan asana maka seseorang akan mendapatkan manfaat seperti memiliki tubuh yang sehat, bernapas lebih baik, meningkatnya kesadaran tubuh, mengatasi stress dan membuat pikiran menjadi lebih fokus. Saat melakukan asana seseorang harus dapat menerima tubuh fisik dan mentalnya. Ia harus fokus pada kesadaran pikiran dan tubuhnya. Dengan begitu ia dapat melakukan asana dengan maksimal.

Menurut literatur dari berbagai kitab suci, Dewa Siva adalah pendiri dari ajaran yoga, termasuk didalamnya asana. Beliau menciptakan semua asana dan mengajarkannya pada muridnya yang pertama, yakni Parvati (Sarasvati, 2002:7). Dikatakan bahwa semula ada 8.400 .000 asana yang menunjukkan 8.400 .000 inkarnasi dimana setiap orang harus melewatinya sebelum mencapai pembebasan dari siklus kelahiran dan kematian.
Asana-asana ini menggambarkan perubahan yang progresif dari bentuk kehidupan yang paling sederhana menjadi manusia yang benar-benar sadar. Dipercaya bahwa dengan melakukan semua itu seseorang dapat melintasi semua kehidupan ini dalam satu kehidupan dan menyongsong kemajuan yang menentukan dari satu kehidupan ke kehidupan berikutnya.

Selama ini asana yang ada telah diubah dan dikurangi jumlahnya oleh para rsi dan para yogi yang terkenal sehingga saat ini tidak lebih dari beberapa ratus yang diketahui. Dari jumlah ini hanya delapan puluh empat yang dibicarakan secara terperinci dan hanya tiga puluh lebih yang biasanya diingat karena berguna bagi orang modern. Sebagian besar orang pada tahun belakangan ini, terutama remaja telah berpaling pada penggunaan obat-obatan, ganja dan lainnya untuk mencari perhatian dan makna dalam kehidupan mereka. Yoga pada umumnya, termasuk asana, merupakan cara yang sempurna bagi seseorang untuk menemukan makna baru dalam hidup. Berbagai obat-obatan terbatas dalam jangkauan mereka, sedangkan latihan yoga akan membawa seseorang pada kesadaran spiritual.

Beberapa postur dan pose asanas adalah alami, alami yang dimaksud adalah pose dan posturyang ada terbentuk karena terinspirasi oleh berbagai pose yang ada di alam semesta, kapanpun keadaan praktik seseorang dengan sadar ataupun tidak sadar mengadopsi postur dan pose yang tepatbagi kesehatan dan kebugaran tubuh dan mentalnya. Jika seseorang merasa cemas, maka secara tidak langsung akan menghilangkan kekhawatirannya melalui pose yang dilakukannya.

Salah satu pose asana adalah Janu Sirsasana. Secara etimologi kata Janu Sirsasana berasal dari dua suku kata, yakni janu dan shiras. Janu adalah lutut dan shiras adalah menyentuh dengan kepala. Jadi Janu Sirsasana adalah praktek yoga asana yang dilakukan dengan menyentuhkan kepala pada lutut. Lutut yang disentuh oleh kepala bukan kedua lutut, melainkan hanya salah satu 
lutut, setiap melakukan pose asana ini dengan cara bergantian baik dengan meluruskan kaki kanan ataupun dengan kaki kiri.

Janu Sirsasana yang disebut juga sebagai maha mudra oleh beberapa orang, terdiri dari tiga jenis, yang masing-masing memiliki vinyasas. Metode Janu Sirsasana adalah pada titik pernapasan dengan melibatkan penarikan dan penghebusan napas yang sebaiknya dipelajari dengan tuntunan dari seorang guru. Janu Sirsasana dapat dipraktekkan oleh siapapun, laki ataupun perempuan, muda ataupun lansia, tanpa batasan jenis kelamin.

\section{Cara Mempraktekkan Pose Janu Sirsasana}

Pose Janu Sirsasana adalah pose yang dilakukan dengan duduk menekuk ke depan. Dengan konsentrasi spiritual ditujukan pada svadhistana cakra, dan konsentrasi fisik ditujukan pada perut, pengendoran otot-otot punggung atau proses pernapasan yang perlahan-lahan. Gravitasi bekerja untuk menarik tulang punggung kea rah kaki yang direntangkan/ diluruskan. Cara melakukan pose ini adalah sebagai berikut:

Duduklah dengan kedua kaki direntangkan di depan tubuh

Lipatlah salah satu kaki dan letakkan tumit pada selangkangan, telapaknya menyentuh pada paha yang satunya lagi. Tahanlah lutut pada lantai dengan tidak menekuknya. Pastikan kaki yang ditekuk tidak berada di bawah kaki yang posisinya lurus. Luruskan kaki di atas lantai dan tekan tumit ke arah selangkangan bagian dalam dari kaki yang lurus.

Bersandarlah ke depan dan pegang jari-jari kaki yang lurus atau telapak kaki dengan kedua tangan

Lalu tariklah tubuh ke depan secara perlahanlahan sehingga kepala berada di atas lutut yang lurus, lalu ulangi proses tersebut dengan kaki lainnya yang dilipat. Untuk memperoleh hasil yang maksimal lakukan pose ini sebanyak 2 hingga 3 set.

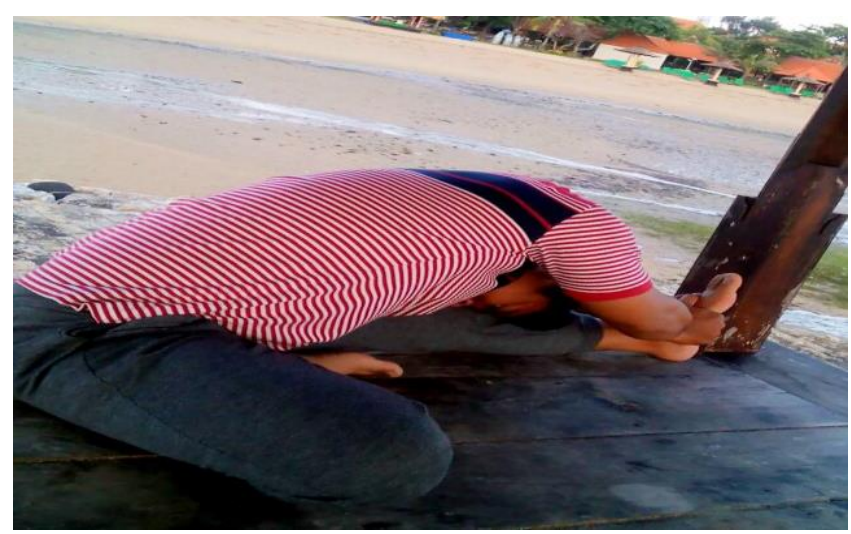

Gambar 1. Pose Janu Sirsasana

Pernapasan bisa sangat membantu proses maksimalnya saat pose ini dilakukan. Dengan menekankan upaya mengeluarkan napas akan menambah fleksi pada panggul. Sedangkan menekankan upaya menarik napas akan membantu merentangkan ulang belakang atas. Ini hanya akan terjadi kalau upaya mengeluarkan napas diawali dengan otot-otot perut bawah dan menarik napas diarahkan ke tulang rusuk. Sekalikali dapat dilakukan dengan proses napas yang berbeda, keluarkan napas dengan memompa dada dan tarik napas ke daerah perut. Perhatikan efek asana ini bila dibandingkan dengan saran pertama. Hembuskanlah napas saat membungkukkan tubuh ke depan, tahanlah napas jika bertahan pada sikap akhir dalam waktu yang singkat. Bernapaslah dengan normal jika sikap badan tersebut ditahan dalam waktu yang lama. Tariklah napas saat kembali ke posisi duduk. Pose ini dapat dilakukan beberapa kali selama 10-15 detik, jika sudah mahir maka pose ini dapat dilakukan hingga lima menit dengan bertahan dalam posisi akhir dengan pengendoran yang sempurna dalam waktu yang cukup lama.

\section{Fisiologi Janu Sirsasana}

Pose asimetris ini semakin mengungkapkan adanya masalah sisi yang terjadi pada otot-otot punggung. Janu Sirsasana juga mengungkap 
masalah pada sisi stabilitas atau mobilitas relatif sendi-sendi sakroiliaka. Setiap orang memiliki sisi mudah dan sulit pada pose ini karena sifat dari asimetris tubuh manusia. semakin aktif sendi sakroiliaka pada sisi kaki yang menekuk, maka semakin mudah sendi tersebut berputar dan menghadap kaki yang terentang. Saat fleksi pinggul bertambah dalam, fleksi tulang belakang tidak begitu dibutuhkan, karena batasan ini semakin besar berotasi pada tulang belakang lumbal, lebih banyak gerakan diharapkan terjadi pada sendi sakroiliaka.

Sendi sakroiliaka memang sangat lazim bergerak terlalu aktif dalam Janu Sirsasana. Ini terjadi saat pose tersebut ditarik atau ditekuk terlalu kuat atau ditahan terlalu lama tanpa melepaskan beban pada panggul. Kemungkinan lainnya imobilitas sendi panggul bisa mengarah ke perputaran yang berlebihan pada sendi lutut kaki yang ditekuk. Semua ini mengarah ke fakta bahwa tekanan pada tulang belakang, sakroiliaka serta sendi-sendi pinggul dan lutut perlu disebar merata, sehingga tidak ada satu struktur pun mengalami semua tekanan tersebut pada pose ini.

Asanas mempengaruhi setiap aspek dalam tubuh fisik manusia, selain terjadinya keseimbangan kerja kalenjar juga membuat otototot rileks dan giat. Sistem saraf yang bekerja dengan maksimal, menstimulir sirkulasi, mengendurkan otot dan memusatkan pikiran adalah pengaruh dari melakukan asanas. Selama melakukan gerakan-gerakan yang halus, tubuh tetap berada dalam keadaan yang nyaman, pernapasan dilakukan panjang yang menyertai sikap-sikap asanas menjadikan darah menyerap lebih banyak oksigen. Selama masa latihan asanas, tenaga lebih banyak dikumpulkan daripada dipergunakan tubuh.

Pada orang yang normal, otot-ototnya tegang dan jarang berada dalam keadaan yang rileks, sekalipun dalam keadaan tidur. Selalu ada ketegangan tertentu yang disebut basal tension atau muscular tone, yang penting untuk mendapatkan postur tubuh dan konfigurasinya yang normal. Akan tetapi hal ini juga memerlukan energi meskipun dalam keadaan tidak bergerak (tidur). Asanas sebagai kebalikan dari olah raga keras melibatkan kontraksi otot tertentu, dipertahankan dalam jangka waktu tertentu dan diikuti dengan perasaan yang rileks. Setelah melakukan gerakan asanas beberapa waktu, maka sekelompok otot mengutub dan membuatnya menjadi rileks. Dengan kata lain, dengan melakukan asanas seseorang memperoleh secara alami apa yang tidak pernah diperolehnya dari pengobatan oleh obat-obatan yakni membuat rileks pada otototot tertentu. Obat-obatan akan terbatas pada sekelompok otot saja tanpa melibatkan sistem otot tubuh keseluruhannya. Berbagai gerakan sendi, menggerakkan tulang belakang, otot kaki, dan memanjangkan tulang punggung adalah manfaat fisiolofi bagi tubuh dengan melakukan pose ini (Kaminoff, 2010). Perincian fisiologi bagi tubuh dengan mempraktekkan Janu Sirsasana adalah sebagai berikut:

1. Gerakan Sendi

Fleksi (gerak menekuk atau membengkokkan) tulang belakang ringan dan rotasi ringan: sacrum yang berada di ujung tulang belakang, muncul sebagai tulang segitiga yang bernutasi (poros), pada kaki yang terentang: fleksi pinggul, aduksi, rotasi internal, ekstensi lutut, pergelangan kaki dalam dorsifleksi. Kaki yang terlipat: terjadinya fleksi pinggul, abduksi, rotasi eksternal. Fleksi lutut: plantarfleksi pergelangan kaki, supinasi telapak kaki. Pada bahu dan tangan: abduksi tulang belikat, rotasi ke atas: fleksi sendi glenohumeral, sedikit rotasi eksternal, aduksi: ekstensi siku dan sedikit pronasi ke lengan bawah. 
2. Menggerakkan

- Tulang belakang: ekstensor tulang belakang bisa memperdalam gerakan pada sendi pinggul. Oblique internal pada sisi kaki yang terlentang dan oblique eksternal pada sisi kaki yang terlipat bekerja sama untuk memutar tulang belakang menghadap ke kaki yang terentang. Multifidi dan rotator pada sisi kaki yang terlipat bekerja untuk memutar tulang belakang ke arah kaki yang terlentang.

- Kaki yang terentang: gravitasi bekerja untuk menekuk pinggul; vasti dan articularis genus merentangkan lutut.

- Kaki yang terlipat: gravitasi bekerja untuk menggerakkan poros (nutasi) sacrum dan menekuk pinggul. Obturator externus, kuadratus femoris, piriformis, obturator internus dan gemelli secara eksternal memutar pinggul; Sartorius secara eksternal memutar dan menekuk pinggul dan lutut. Hamstring bekerja untuk menekuk lutut serta tibialis depan menekuk pergelangan kaki dan memutar telapak kaki ke luar.

3. Memanjangkan

- Tulang belakang: ekstensor tulang belakang memanjang, kalau dilepas membentuk pose ini. Latisimus dorsi mamanjang secara bilateral. Oblique eksternal sisi kaki yang terentang dan oblique internal sisi kaki yang terlipat, rotator sisi kaki yang terentang, serta multifidi memanjang dengan rotasi ke arah kaki yang lurus.

- Kaki yang terentang: hamstring, gluteus maksimus, piriformis, obturator internus dan gemelli, beberapa gluteus medius dan minimus, gastroknemius dan soleus. Popliteus bisa menimbulkan sedikitkan sedikit fleksi lutut untuk mencegah terjadinya hiperekstensi.

- Kaki yang terlipat: adduktor magnus meregang, karena menimbulkan rotasi, ekstensi dan aduksi internal. Semakin banyak kaki berputar dan menjauhi poros tubuh (abduksi), semakin panjang pektineus.

- Tangan: rhomboid memanan: romboid memanjang seperti juga tra seperti juga trapezius bawah dan latisimus dorsi.

\section{Manfaat Mempraktekkan Pose Janu Sir- sasana}

Secara alami seorang bayi akanmenggerakkan tulang belakangnya secara alamiah dalam posisi yang bermacam-macam, akan tetapi kelentukan ini akan hilang jika tubuh berkembang dewasa. Rata-rata seseorang yang berumur tiga puluh tahun tidak dapat lagi menyentuh lantai dengan jari-jari tangannya bila kedua kakinya berdiri tegak.

Hal ini dikarenakan karena terbatasnya gerak tubuh akibat pemendekan ikat sendi dan otot. Ikat sendi adalah lembaran-lembaran jaringan bersabut, yang menghubungkan satu atau dua buah tulang, tulang rawan dan struktur-struktur lainnya, otot menghubungkan urat-urat ke tulang. Ketika seseorang bertambah tua, maka tulang belakangnya menjadi kaku, karena ikat sendi menjadi kencang. Dan karena struktur ikat sendi saling bersambung, maka apabila gerak pada satu area dibatasi, kelancaran gerak seluruh tubuh akan dipengaruhi.

Setiap gerakan asanas melatih tulang belakang dengan berbagai gerakan seperti: menarik, menekan dan memutar dalam tingkat yang beranekaragam. Semuanya ini mencegah dan memperbaiki posisi tulang belakang yang salah dalam segala posisi, baik itu pada saat duduk, berdiri dan berbaring. Pada zaman dahulu, para yogi dan praktisi yoga telah mengetahui menyadari akan pentingnya kesehatan yang sempurna dari tulang belakang pada tubuh manusia. Berawal dari 
itulah diciptakan berbagai gerakan pose asanas yang dilakukan untuk mendapatkan bentuk tulang belakang yang tepat, seperti sikap kobra, ikan dan memutar tulang belakang (pose matsyendrasana, matsyamudra dan bhujangasana). Gerakan kepala pada lutut (janu sirsasana dan paschimottanasana), menarik tulang belakang sampai pada panjang yang maksimumnya.

Pose ini juga dapat menarik sendi ikat dan otot yang membungkus tulang belakang, dengan demikian dapat membebaskan rasa sakit tekanan pada saraf. Dengan memperkuat otototot tulang belakang, mereka memperoleh bentuk lengkungnya yang tepat. Dalam hal ini, asanas mengembalikan kelentukan tulang belakang seperti pada masa bayi atau kanak-kanak serta dengan melakukan pose ini dapat mencegah rasa kaku yang menyakitkan pada tubuh ketika usia yang makin bertambah.

Berbagaimanfaat yang dapat diperoleh dengan melakukan pose ini antara lain: meregangkan uraturat lutut dan mengendorkan persendian tulang paha. Menghilangkan kelebihan lemak secara efektif pada daerah perut. Menyeimbangkan seluruh organ perut dan menghilangkan berbagai penyakit di daerah perut. Seperti diabetes, asana ini juga mengaktifkan kelenjar ginjal, hati, pankreas dan adrenalin. Menyelaraskan organorgan panggul sehingga bermanfaat terutama untuk menghilangkan penyakit seksual bagi wanita. Merangsang aliran darah segar yang baik ke saraf dan otot-otot tulang belakang. Asana ini merupakan asana yang sangat baik untuk mencapai kesadaran spiritual.

Melakukan yoga asanas dapat melumasi dan melatih persendian dengan menghilangkan "karat" dan mengembalikan gerakan yang bebas dan alami, seseorang yang baru mengikuti kelas yoga akan segera merasakan persendian mereka menjadi lebih tangkas dengan latihan asanas yang berulang-ulang hingga tubuh mereka kembali lentuk dan tangkas seperti masa kanak-kanak dulu.

Menurut yogajournal.com melakukan pose Janu Sirsasana dapat menenangkan otak dan membantu meringankan depresi ringan, meregangkan tulang belakang, bahu, paha belakang dan selangkangan. Merangsang hati dan ginjal, memperbaiki pencernaan, membantu meringankan gejala menopause, meredakan kecemasan, kelelahan, sakit kepala dan ketidaknyamanan saat menstruasi, terapi untuk tekanan darah tinggi, sulit tidur dan sinusitis, menjaga tulang punggung bagian belakang tetap cekung dan dada panjang.

\section{SIMPULAN}

Asana merupakan langkah ketiga dari delapan langkah (astangga yoga) yang dikompilasikan oleh Maha Rsi Patanjali dengan tujuan untuk membuat tubuh mantap bagi teknik-teknik yang lebih tinggi seperti pratyahara (penarikan inderaindera), dharana (konsentrasi), dhayana(meditasi) dan samadhi (realisasi kosmis). Rileksasi yang sempurna dari gerakan asanas, berkaitan dengan penghematan energi yang dapat diarahkan ke dalam diri untuk meningkatkan pikiran pada tingkat kesadaran yang lebih tinggi yakni kesadaran spiritual.

Salah satu pose asana adalah Janu Sirsasana. Secara etimologi kata Janu Sirsasana berasal dari dua suku kata, yakni janu dan shiras. Janu adalah lutut dan shiras adalah menyentuh dengan kepala. Jadi Janu Sirsasana adalah praktek yoga asana yang dilakukan dengan menyentuhkan kepala pada lutut.

Berbagaimanfaat yang dapat diperoleh dengan melakukan pose ini antara lain: meregangkan uraturat lutut dan mengendorkan persendian tulang paha. Menghilangkan kelebihan lemak secara efektif pada daerah perut. Menyeimbangkan 
seluruh organ perut dan menghilangkan berbagai penyakit di daerah perut. Seperti diabetes, asana ini juga mengaktifkan kelenjar ginjal, hati, pankreas dan adrenalin. Menyelaraskan organorgan panggul sehingga bermanfaat terutama untuk menghilangkan penyakit seksual bagi wanita. Merangsang aliran darah segar yang baik ke saraf dan otot-otot tulang belakang. Asana ini merupakan asana yang sangat baik untuk mencapai kesadaran spiritual.

\section{DAFTAR PUSTAKA}

Satchidananda, Sri Svami. 1978. The Yoga Sutras Of Patanjali. India : Yoga Publications.

Sarasvati, Svami Satyananda. 2002. Asana, Pranayama, Mudra, Bandha. Surabaya: Paramita

Sarma, Rajeev. 2005. Yoga For All. Delhi: Manoj Publications.

Vasu, Srisa Candra. 1979. Gheranda Samhita.

Delhi: Sri Satguru Publications. 